\title{
HERMENEUTIC CHANGE OF THE SCIENTIFIC APPROACH TO MYTHS AND FUNCTION OF SYMBOLS IN THE CULTURES OF THE ANCIENT MIDDLE EAST
}

\begin{abstract}
In Slovakia, the older generations consider everything connected with religion a priori in the negative sense, because the previous regime led them to treat all such religious interpretations of life as legends or fairy tales. However, in the scientific world today, there is a significant change in the approach to the ancient literature, to its myths and old stories - epic poems of the humanity. In the absolute terms, myth communicates its content via symbols which convey its inner meaning. Nowadays, myths, epic poems, ancient literary works and literary units are considered to be narrative literary genres that were used by an archaic man for an explanation of events and facts that s/he could not explain in a satisfactory way or for hiding what is today referred to as scientific knowledge.
\end{abstract}

Keywords: hermeneutics, myth - epic poem, symbol, interpretation, ancient genres, ancient cultures, the ancient Middle East

\section{Myth, mythology and its older interpretation}

Mythical or mythological narrations are, or seem to be, arbitrary, improbable, meaningless and absurd, yet they seem to reappear all over the world. Since the advent of science, mythology has been rejected as a product of superstitious and primitive minds. However, it is important to come to a fuller appreciation of the nature and role of myth in human history [1, pp. 7, 19]. In Slovakia, the older generations consider everything connected with religion a priori in the negative sense, because the previous regime led them to treat all such religious interpretations of life as legends or fairy tales [2, p. 54]. This tendency still has a high percentage of followers as the word myth is still quite often used in the stated meaning. However, we are rarely aware of the real meaning of myth, so it is rather confused with something false and mocking. Even if the scientific world of today has significantly changed its approach and worked on more exact scientific clarification of the phenomena, in the Slovak literature one can still find superficial understanding of the myth and mythology. It is evident from the following characteristics that are still present in dictionaries: "mythology, ...fairy tale narration..., ...irrational vision..., ...picture of someone or of something that is uncritically accepted, worshiped and adored, ...fantasy, delusion ...” [3, p. 623] and "figuratively. misleading deceitful belief in something: rebut myth of your infallibility; myth of mystery" [4].

\section{Myth, mythology and its systematic scientific research}

However, it is important to come to a fuller appreciation of the nature and role of myth in human history, as the scientific world has significantly changed its approach to ancient literature, its myths, mythologies, and old stories at all. Myth is speaking in symbols, and an archaic people used it to express and explain the origin and goal of human being as well as of the world where they lived. Therefore, the myth has nothing in common with fictional fables and does not reflect the fictional reality that is offered and pictured in contemporary literature. Myth reflects reality experienced by people, apart from the fact whether it can or cannot be proved by the history [1, pp. 9, 17]. Myth cannot be approached from the historical perspective as the time of the stories is not determined. Thus, myths and mythologies talk about the creation of the universe - cosmology, the origin of gods - theogony, and arrangement of the universe - cosmology. They explain events, phenomena and the cycle of nature. They deal with the beginning and the end, with the creation and the destruction, life and death. At the same time, they describe everyday life of a man, history of nations and their desire for a better life [5, pp. 9-11]. Myth and mythical relation to the world gave all ancient cultures their obvious horizon; it enabled and expressed - understood their life. Mythical perception presents interconnection of natural and social events. In the stricter sense,

\footnotetext{
* Daniel Slivka

Department of Historical Sciences, Greek Catholic Theological Faculty, University of Presov, Slovakia

E-mail: daniel.slivka@unipo.sk
} 
myth presents this unity on the concrete examples of characters, situations etc. that are from the very beginning connected with existential and ontological issues [6, pp. 9-11].

Therefore, mythology can be defined as the study „of myths in general or from the perspective of certain cultural or religious tradition in individual periods or civilizations" [7, p. 717] or as a system or a complex of elements forming the civilized and intellectual foundations of the society, morality, religion, etc.: where mythology „explains the system of social and ethical standards, ritual, and art of a community and at the same time it presents its individual history that reveals the creation of the world, the Earth, man, tribe, its culture and the law that states standards of conduct, in the light of acts of gods and heroes, it determines rites that should remind descendants significant acts of their great ancestors" $[8$, p. 6]. Myth plays an important role in tribal societies. It justifies the system of social and ethical standards, rituals and art; it keeps a collective history of the community, its laws, habits, traditions. It also deals with the creation of the world, the country of man, tribe, nation, with its history and culture, morals and rights as well as it dictates standards of conduct. In the beginning, mythological thinking overlapped with the religious one. Focusing on religion, dominant elements are cult and worshipping of gods by prayers, sacrifices, rituals which employ various magical means, spells, incantations, and prophecies. On the contrary, mythology is based on mythmaking, on the creation of mythological stories rather than epic narrations. With the development of writing, myths became fictionalized independently of religious belief $[9$, pp. 20-23].

Myths may be connected with numerous cultures and also present newly processed old traditions which also contain explanations connected with certain significant persons, groups and are adjusted for the needs and expectations of periods of their origin [10, p. 50]. In the history of ancient Greece, in the period of oral culture, mythological sayings, songs, and poems were integral parts of the life of society. As myths did not have stable form, a tale-teller used their flexibility and adjusted the story according to listeners. Thus, the tale-teller could modify the story in order to reflect all moral and cultural requirements of a given era and appeal on the life situation of the audience [11, p. 12].

Myth has the original narrative form, but it is at the same time based on oral storytelling. Consequently, it is often unclear and ambiguous. People tell stories that spread further, and while doing so, they also change. On the other hand, when stories are often told and spread, there are certain themes or even idioms that tend to reappear in them again and again. After a certain period of time, no one knows whether so many times repeated version of the story corresponds to an original event that really happened. Even if myths occur in several versions, they always contain similar themes and idioms. Due to the high number of characters and ambiguity of its meaning, it is a great advantage of the myth that one of many stories always reflects something. The presentation of myth depended on a situation, and it gave this situation certain meaning. The gradual development of the society, thinking, and artistic imagination, as well as adoption of natural phenomena, made mythological images more rational and artistically more sophisticated. Gods and heroes took the form of animals or people. Mythology had a massive influence on all spheres of spiritual life. Every nation created its own myths, tales, and legends. These stories reflect spirit - the soul of the nation, its thoughts, hopes, desires, its ideas about existence, nature and the life itself. The gods of the ancient Middle East, as powers of nature and society, ruled over a human being and were people's religious-mythological expression. These gods who represented everything that affected people were their outer models as well as the inner substances [12, pp. 51].

Besides its basic cosmological and mystic function, myth also has the following functions: [8, p. 55].

- social function - myths offer models and principles of behavior, practical behavior in the society and incite concrete acts,

- pedagogical function - myths present ways and reactions of everyday life and they also contain parts dealing with the theme of life happiness of people,

- interpretative function - myths give reasons to life and religious ceremonies, explain human behavior in the social system and its forms.

Myths have symbolic as well as sacred value, and they formed the basis of old nations. They gave people answers to basic questions. However, what was obvious to the ancient people is many times distant and incomprehensible to the modern man. It is necessary to realize that during the major part of the history "homo sapiens" identified with "homo religious" for a simple reason - it was against principles of nature and world order not to be "homo religious." And it is also the reason why "from the beginning, myth was always connected with religion and many times with the religious ceremonies too. It took quite a long time till myths were written down as they originally existed in the society in the spoken form. Myth formed the basis of law, social and political life of the archaic societies" [13].

Contemporary people understand ancient religious phenomena in their literary sense. However, if they are not studied to the depth, they may seem trivial. Mythology forms the primary basis of ideas of the social organization, the world opinion, religion, morals, law, etc. Myths passed from generation to generation, and they explained the mystery of existence, the origin of the world, the reason of suffering and death [14, pp. 62-69], origin of traditions and provisions, the secret of love and life" [15, p. 144].

Even beginnings of philosophy are sometimes hidden by the mythological pictures. Myths offer a certain picture of the world. Thus they represent sort of preliminary stage of philosophy. Therefore, mythology is also called protophilosophy or early metaphysics $[16$, p. 29]. The Greeks managed to deal with suggestions based on mythological narrations in their own 
original way until the term "mythos" was detached from the word "logos" which subsequently led to the beginning of the era of philosophy [17, p. 92-94].

\section{Myth, mythology as a narrative genre}

"Myth as a narrative literary genre has its own right as well as a preferred place: which is to deal with the beginning of the world and mankind which is radically out of our experience and human deductive way of thinking. In this way, it is a "myth about beginnings," thus it is a narration describing early events of the world and human being. This myth employs archetypical characters as protagonists and archetypical early facts as well as human behavior in order to disclose and explain them. Moreover, the myth deals with the universal symbols that concentrated the first explanation of significant questions connected with the human existence, such as limited being, our mortal nature, our sexual differentiation, etc. To achieve this, the myth creates a narration where the reality is presented through the concrete events that are offered as a story - narration that happened at the beginning of the time and is used as a template for the human behavior. The myth about beginnings approaches the reality in the opposite way as, for example, the logical speech of philosophy or science" [2, p. 58].

From the literary point of view, myth is an epic genre. The author is anonymous, and it is passed by traditions for many generations. It is mystic because it connects man with the transcendent. While reading a myth, people must employ their spiritual ability to understand that the greatness of the myth lies in the simplicity of the mythical story. Myth uses the language of symbols, and a symbol is at the same time the language of religion [18, p. 402]. Mythological epos includes [19, p. 94]:

divine inspiration,

ancient social tradition as a result of numerous generations, its own approach and interpretation of the reciter,

it does not form a uniform unit of interconnected narrations; it may contain several time layers,

it is important to recognize what aspects of mythology are connected with the reality and what presents a fiction of life.

"Therefore, myth can be equated neither with a made-up fable, which is a creation of a human naivety nor with a fictional reality dressed in a literary veil. Personification and dramatization are stylistic means of illustration and plasticity of the mythical narration" [7, p. 718]. The typical feature of the myth is narration. Narration is a macro-compositional mean of text formation, and it is based on verbs, story, and plot. It may contain direct speech and various forms of narrators. Sometimes, it uses special techniques of delivery, as it can be delivered, for example, by singing. To update the story, the timing of motives is typical for myth [20]. It does not have an author, but it has a narrator. It is one of the basic features of myth that it lost reference to any author. Narration may have the character of literary analysis that focuses on people and their actions in the story. Moreover, the narration of the story should attract readers and take them to the world of values presented by the story. The most dominant are mythological stories about the creation of the world that can be found in all ancient cultures [18, p. 402].

\section{Function of symbols}

According to discoveries, ancient texts (now literary texts) contain awareness and knowledge which is present in the constituted human experience that is then represented in myths and symbols of humanity [21, pp. 151-152]. Myth also becomes a universal model for individual and collective actions, because it is also the source of mysterious experience and life knowledge [22, pp. 25-26] as a special type of social interaction and communication via symbols [8, p. 29]. Symbols are not rigid, precisely defined units, but they are variable (unfixed) because their meaning depends on the way of the expression of the phenomena [23, p. 13]. In literature, the symbol has multiple meanings, and it does not have defined boundaries [24, p. 343].

Mythological narration largely employs the language of symbols. However, interpretation does not depend on reason and science which is a measure of everything, today. It is for the hermeneutics, as the art to interpret ancient texts, to search, find and adopt this knowledge which has always been present in human learning in a certain way. This knowledge is hidden in the form of already realized and constituted human experience, in its intuition which is represented by myths and symbols. Therefore, Ricoeur says: "Symbols and myths give rise to the thought," and this quotation poses two things [2, pp. 54-56]:

- firstly, it states that "symbol gives" which means that it is not "me" who gives reason to the reality, but it is a symbol that enables us to understand. This symbol is determined by the religious text or ceremonies. For instance, available are symbols of tree, snake, water, fire, bread or the Credo of the Church, etc.

- secondary, biblical symbol enables "thinking" or understanding. It makes it possible for an intellectual thinking ability to develop. It does not close the human thinking behind the dogmatic brackets, but it provokes and boosts the thinking process as it forces to repeat utterance again and again and revise it in its own experience.

Ricoeur expresses an important idea that our thinking develops when it focuses on a secret or a mystery hidden inside of a symbol or a myth that need to be discovered. It presents the possibility to develop intellectual ability and thinking.

Myths contain symbols, metaphors, and models. Symbol has a deep communicative ability, and it drives a reader to participate in an intended meaning. The language of symbols can express the most difficult ideas as it goes beyond the ability 


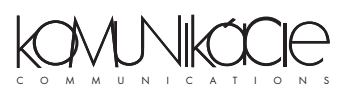

of any finite reality. " $H$. Halbfas, the significant German religious lecturer, turns his attention firstly towards the lexical meaning of the word symbol: in the ancient world, Greek word symballein meant something like "to mell, to connect, to unite. Then, a broken ring which identified envoys of two friends was called symbolon. The word presents the synthesis, connection, heading towards the only unity, mutual complementation of elements which have been parted at the beginning standing one against another. Halbfas claims that people cannot understand symbol when it is defined only in a rational way because it destroys its internal content and then we can see only the coat. Therefore, symbols cannot be arbitrarily established. Naturally, there should be a given critical position within scientific measures, but in order to reach the inner meaning of a symbol, one needs another sense, something like an inner sense for understanding symbols. However, even if it is a necessary condition for treating with symbols, not anyone possesses this sense" [2, p. 54].

\section{Conclusion}

The original aim of mythology was to help people cope with critical human questions. Mythology helped people to find their place and orientation in the world. Myths carry a mystery of human existence, and they are written in a language of symbols. Therefore, it is necessary to decode myths to understand them. Myths are often connected with transitional rituals of life, and they seek to create a structure that will enable people to understand the whole life. Time and place are also symbolic, thus myths about the beginning should be interpreted in such a way as to deal with everything that happens during human life. If certain conditions are met, myths can play a constructive role in affirming that the "human person's dignity is inalienable and indisputable, for in their necessary albeit often unrecognized relatedness to transcendence, human persons have a transcendent source and destiny" [25, p. 289].

Myths should also be studied in the context of original communities that had certain religious perspective and interpretation of life [26, pp. 137-139]. The common element of the language of symbols is a picture and a metaphor. They have a common nature which is to collect and express a number of features in one word, as they appear immediately and at once. Nowadays, myths, epos, ancient literary works and literary units are narrative literary genres that were used by an archaic people who tried to explain events and facts or where they hid what is now known as logical scientific knowledge.

\section{References}

[1] LEVI-STRAUSS, C.: Myth and Meaning (in Slovak). ARCHA, Bratislava, 1993.

[2] LESCINSKY, J.: Dynamic Anthropology of Bible (in Slovak). Verbum, Kosice, 2004.

[3] Dictionary of Foreign Terms in Slovak. SPN, Bratislava, 1997.

[4] Dictionary of the Slovak Language, Myth [online]. Available: http://slovnik.azet.sk/pravopis/slovnik-sj/?q=m\%C3\%BDtus [accessed 2017-08-20].

[5] ESTINOVA, C., LAPORTEOVA, H.: Greek and Roman Mythology (in Slovak). Mlade leta, Bratislava, 1994.

[6] KRATOCHVIL, Z.: Myth, Philosophy and Science II (in Czech). Charles University, Faculty of Education, Department of Social Sciences and Philosophy, Praha, 1991.

[7] HERIBAN, J.: The Hand Lexicon of Biblical Science (in Slovak). Pontifical Slovak College of St. Cyril and Methodius in Rome, Rome, 1992.

[8] KARDIS, M.: Mythology (in Slovak). GTF PU, Presov, 2009.

[9] KOMOROVSKY, J.: Religious Studies (in Slovak). Comenius University, Bratislava, 2000.

[10] REBENICH, S.: 101 Most Important Questions: ANTIQUITY (in Slovak). TeMi CZ, Velke Bilovice, 2007.

[11] PANCZLOVA, H.: St. Gregory of Nyssa: Commentary of the Book of Song of Songs (1. part) Prologue and Homily 1 - 5/Sv. Gregor z Nyssy: Vyklad Velpiesne (1. cast) Prolog a Homilie 1 - 5 (in Slovak). Initial Study, Dobra kniha for TF TU, Bratislava, 2015.

[12] KESIDI, CH. F.: From Myth to Logos (in Slovak). PRAVDA, Bratislava, 1976.

[13] MODOROSI, I.: What is Myth? (in Slovak) [online]. Available: http://www.tyzden.sk/casopis/2009/1/co-je-mytus.html [accessed 2010-11-13]

[14] PAVLIKOVA, M.: Consciousness of Anxiety in Literary Work of Don de Lillo. XLinguae, 10(1), 62-69, 2017; see also: AMBROZY, M. KRALIK, R., Martin, J. G.: Determinism vs. Freedom: Some Ethics-Social Implications. Xlinguae, 10(4), 48-57, 2017; KRALIK, R.: Kierkegaard's Interpretation of Faith. XLinguae, 10(3), 37-44, 2017; KRALIK, R., TINLEY, S. J.: Kierkegaard's Ethics as an Answer to Human Alienation in Technocratic Society. Communications - Scientific Letters of the University of Zilina, 19(1), 25-29, 2017; LESKOVA, A., VALCO, M.: Identity of Adolescents and its Dimensions in Relation to Mass Media: 
Philosophical-Ethical Reflections. XLinguae, 10(3), 324-332, 2017; VALCO, M., BOEHME, A. J.: Christian Faith and Science Can Science Enhance Theology? European Journal of Science and Theology, 13(3), 89-97, 2017; VALCO, M. KRALIK, R., BARRETT, L.: Moral Implications of Augustine's Philosophical and Spiritual Journey in his Confessiones. Communications - Scientific Letters of the University of Zilina, 17(2), 103-108, 2015; VALCOVA, K, PAVLIKOVA, M., ROUBALOVA, M. Religious Existentialism as a Countermeasure to Moralistic Therapeutic Deism. Communications - Scientific Letters of the University of Zilina, 18(3), 98-104, 2016.

[15] TRUTWIN, W., MAGA, J.: He Has Opened Scripture. Introduction to the World of Biblie/Otvaral nam pisma: Uvod do sveta biblie (in Slovak). Knazsky seminar biskupa J. Vojtassaka, Spisska Kapitula, 1993.

[16] STOLARIK, S.: A Short History of Philosophy (in Slovak). Seminar sv. Karola Boromejskeho, Kosice, 2007.

[17] STORIG, H. J.: A Small World History of Philosophy (in Czech). ZVON, Praha, 1995.

[18] MOCNA, D., PETERKA, J.: Encyclopedia of Literary Genres (in Czech). Paseka, Praha, 2004.

[19] HOSEK, R.: Religion of Ancient Greece (in Czech). Vysehrad, Praha, 2004.

[20] Slovak Language and Literature, Literary Terms „R“ (in Slovak) [online]. Available: http://www.sjl.estranky.cz/clanky/literarnepojmy/literarne-pojmy-r of [accessed 2010-11-20].

[21] ELIADE, M.: History of Religious Ideas, Volume 1 (in Slovak). AGORA, Bratislava, 1995.

[22] BAK, T. JURJEWICZ, H., MIERZWA, J.: Religion and Spirituality in Social Work Practice. Diocesan House of Formation Bartimaeus New Jersey, New Jersey, 2015; see also: KONDRLA, P., REPAR, P. Postmodern aspects of New Religious Movements. European Journal of Science and Theology, 13(3), 67-74, 2017; KONDRLA, P., TOROK, L. Objective Faith, and Weak Truth. European Journal of Science and Theology 13(3), 79-86, 2017; VALCOVA, K.: Thinking with Kierkegaard about Current Challenges in our 'Practice in Christianity'. European Journal of Science and Theology, 12(2), 203-212, 2016.

[23] LURKER, M.: Dictionary of Biblical Pictures and Symbols (in Czech). Vysehrad, spol. s.r.o., Praha, 1999.

[24] PAVERA, L., VSETICKA, F.: Dictionary of Literary Terms (in Czech). Nakl. Olomouc, Olomouc, 2002.

[25] VALCO, M., STURAK, P.: The "Relational Self”: Philosophical-Religious Reflections in Anthropology and Personalism. XLinguae, 11(1XL), 289-299, 2018.

[26] COLE, P.: Philosophy of Religion. Portal, Praha, 2003. 